\title{
CONTRIBUIÇÕES DO DESIGN DIGITAL PARA A INCLUSÃO DE DEFICIENTES AUDITIVOS
}

\author{
Rita de Castro Engler \\ Universidade do Estado de Minas Gerais \\ rcengler@uol.com.br \\ Nadja Maria Mourão \\ Universidade do Estado de Minas Gerais \\ nadjamourao@gmail.com \\ Flavia Neves de Oliveira Castro \\ Universidade do Estado de Minas Gerais \\ eudisseflavia@hotmail.com \\ Antonnione Franco Leone Ribeiro \\ Universidade do Estado de Minas Gerais \\ hardleone@gmail.com
}

Resumo: A partir da Declaração Universal dos Direitos Humanos (1948), o ser humano com deficiências passou a ser considerado integrante da sociedade. $\mathrm{O}$ assunto tem sido abordado nos últimos anos, mas ainda não atende de forma adequada esses cidadãos. Foram sancionados decretos e leis que beneficiam as pessoas com deficiência nas áreas de educação, saúde, acessibilidade e outras. Na prática, muitas normas não funcionam, prevalecendo uma grande dificuldade e falta de preparo em todas as áreas, para lidar e incluir a pessoa com deficiência na sociedade. A legislação garante o acesso dos deficientes ao ensino público, porém, as escolas não se encontram preparadas para atender aos anseios e necessidades dos surdos. A pesquisa procura investigar e propor soluções tecnológicas, para suprir as necessidades educacionais dos deficientes auditivos. Quanto à forma de abordagem do problema, define-se como pesquisa qualitativa, sob a ótica do design para inclusão. Como resultado observa-se o gradativo aumento de investimentos no setor de tecnologias inclusivas. São destaques as contribuições do design, que buscam projetar soluções que possam facilitar a inclusão de alunos surdos. Permanece no sistema educacional, a busca pela igualdade de condições de aprendizagem para todos.

Palavras-chave: Inclusão, deficientes auditivos, educação, design. 


\begin{abstract}
After The Universal Declaration of Human Rights (1948), disabled human started to be considered as members of society. Although this issue has been addressed in recent years, it does not yet meet these citizens' needs. Acts and laws that benefit people with disabilities in the areas of education, health, accessibility and other sanctions have been approved. In practice, many rules do not work properly, and we observe great difficulty and lack of preparation to address and include people with disabilities into society, in all areas. The legislation ensures access of disabled people to public education, but the schools are not prepared to meet the desires and needs of the Deaf. This research seeks to investigate and propose technology solutions to meet the educational needs of the Deaf. Our approach in this research is defined as qualitative research, from the perspective of design for inclusion. As a result we observe the gradual increase of investments in inclusive technology sector. It is highlighted the design contributions that seek solutions which can facilitate the inclusion of Deaf students. The quest for equal learning conditions for all is still an issue in actual educational system.
\end{abstract}

Keywords: Inclusion, Deaf, Education, Design.

\title{
1. INTRODUÇÃO
}

É considerável o recente progresso das conquistas que favorecem a participação dos surdos em diversas atividades sociais. O design universal, como facilitador de inclusões sociais, através de tecnologias aplicadas em função do ser humano, se estabelece potencialmente na sociedade, conforme Bieling e Joost (2012). A comunicação, enquanto fator de integração social, e a educação, como formador do futuro sujeito sociocultural, são predicativos para que esta pesquisa possa analisar hipóteses de melhorias para a educação regular de portadores de deficiência auditiva.

A pesquisa intenta por desenvolver solução tecnológica para suprir as necessidades educacionais dos portadores de deficiência auditiva. Esta produção tem como pensamento estrutural os métodos do design, devida a sua relevância como fomentador da cultura material, e mais ainda, proponente de soluções para o bem estar social. Dentre as suas vertentes, o design para inclusão é aquele que norteia as reflexões e investigações recorrentes a esta pesquisa.

Este trabalho fundamenta-se na pesquisa "Design para Inclusão de Portadores de Deficiência Auditiva", fomento da Fapemig - Fundação de Amparo à Pesquisa do estado de Minas Gerais, com previsão de conclusão em três anos, a partir de agosto de 2013, pelo edital 13/2012, Pesquisa em Educação Básica - Capes/Fapemig.

Os objetos da pesquisa são: investigar autores que tratam da temática da utilização de ferramentas do design para a inclusão da pessoa com deficiência na educação básica; estudar exemplos de projetos de design para a inclusão da pessoa com deficiência auditiva; desenvolver novas aplicações com o auxílio do design digital para a inclusão da pessoa com deficiência auditiva; estimular o desenvolvimento da pessoa com deficiência auditiva durante o ensino básico; promover a potencialidade e a inserção da pessoa com deficiência na sociedade e promover a valorização e inclusão da pessoa com deficiência, através da conscientização da população sobre a importância da inclusão. 
Assim, neste primeiro ano, foram realizados registros da revisão bibliográfica e dos métodos de ensino para surdos, inclusão digital e análises, na perspectiva do design, que são apresentados neste artigo.

\section{DESENVOLVIMENTO}

A metodologia da pesquisa, do ponto de vista de sua natureza, pode-se dizer que é uma pesquisa aplicada. Quanto à forma de abordagem do problema, define-se como pesquisa qualitativa, fundamentada na metodologia da pesquisa-ação, havendo interpretação de dados e atribuição de significados, elementos fundamentais para o método de abordagem.

Conforme Martins (2004) a pesquisa qualitativa é definida como aquela que privilegia a análise de microprocessos, através do estudo das ações sociais individuais e grupais, realizando um exame intensivo dos dados, e caracterizado pela heterodoxia no momento da análise.

Referindo-se aos objetivos é uma pesquisa exploratória, visto que busca proporcionar maior integração com o problema, através de pesquisas de campo e entrevistas. O método de investigação é o estudo de caso, utilizando-se a observação qualitativa, participativa e questionários abertos e semiestruturados.

A região da metrópole mineira é definida como objeto da pesquisa, envolvendo escolas públicas da educação básica, instituições do ensino especial, associações para deficientes auditivos e professores de Libras e pessoas com deficiência auditiva.

A realização do projeto se divide nas etapas de mapeamento, planejamento, execução e finalização. O mapeamento permite a identificação de trabalhos já realizados no âmbito do design, voltado para novas tecnologias que atuem ou possam ser adaptadas para a inclusão da pessoa com deficiência. A etapa de planejamento consiste na preparação para a execução do projeto; definição de materiais que serão utilizados; estabelecimento de contato com profissionais da área digital e áreas correlatas. A execução se inicia com a realização de um focus group ${ }^{1}$ com a participação dos atores envolvidos, na busca de ideias para produtos, processos e serviços que permitam a inclusão dos deficientes no ensino básico. A partir de estudos de caso, espera-se desenvolver novas aplicações por meio do design digital, que possibilitem a inclusão da pessoa com deficiência auditiva. A etapa final consiste na elaboração de material dissertativo, adaptado para publicação em cartilha ou livro. Este material é a base para realização de seminários educativos com foco no ensino.

\subsection{História da educação para com os deficientes auditivos}

$\mathrm{Na}$ história da humanidade, guarda-se uma ideia muito negativa da surdez, enfatizando sempre os seus aspectos negativos. Segundo Goldfeld (2002), na antiguidade, os surdos foram percebidos de diversas formas: com piedade $\mathrm{e}$ compaixão, como loucos, pessoas castigadas pelos deuses ou como pessoas enfeitiçadas. Por isso mesmo, foram abandonadas ou sacrificadas.

Não havia preocupação com a educação dos deficientes auditivos, observação que pode ser garantida pela crença de importantes filósofos como Aristóteles, o qual

\footnotetext{
${ }^{1}$ Uma discussão objetiva, conduzida ou moderada que introduz um tópico a um grupo de respondentes e direciona sua discussão sobre o tema, de uma maneira não estruturada e natural. (PARASURAMAN, 1986: 245)
} 
acreditava que o pensamento era desenvolvido por meio da linguagem falada, portanto concluindo que "[...] o surdo não pensa, não pode ser considerado humano." (GOLDFELD, 2002, p. 24).

No início do século $\mathrm{XVI}$, existem registros das experiências do médico pesquisador italiano Gerolamo Cardano sobre pessoas surdas. Em seus estudos, Cardano conclui que "a surdez não prejudicava a aprendizagem, uma vez que os surdos poderiam aprender a escrever e assim expressar seus sentimentos" (JANNUZZI, 2004, p.31).

Segundo Poker (2004), neste mesmo século o monge beneditino Pedro Ponce de Leon (1520 - 1584) fundou a primeira escola de surdos, na Espanha, desenvolvendo uma metodologia de educação para crianças com surdez incluindo a datilologia. Este método integrava um tipo de representação manual das letras do alfabeto além da escrita e da oralização.

No século XVIII, na França, Abade Charles Michel de L'Epée inicia uma linguagem para as pessoas surdas, denominada como "Sinais Metódicos". L’Epée obteve grande êxito como educador e acabou transformando sua casa em uma escola pública, conforme Poker (2004).

No Brasil, a primeira instituição para surdos foi fundada em 1857, no Rio de Janeiro com o apoio de D. Pedro II, pelo professor surdo francês, Ernest Huet, denominada como Instituto Nacional de Surdos-Mudos, atual INES - Instituto Nacional de Educação dos Surdos. Assim, iniciou-se a Língua de Sinais, passando a trabalhar com oralismo puro, em 1911. Finalmente, por volta de 1970, adotou-se a comunicação total, conforme Brito (1993).

\subsection{Regulamentação da educação Inclusiva}

Em 2002, foi decretado a Libra como forma de comunicação e expressão formal em todo o território brasileiro, através da oficialização da Língua de Sinais Brasileira, Lei Federal no 10.436, de 24 de abril de 2002.

Para a inclusão dos deficientes auditivos, a língua oficial brasileira é a Libras, a segunda língua em território nacional é o português. Para a comunicação em Libras deve-se atentar aos seus cinco parâmetros: configuração de mãos, movimento, orientação das mãos, ponto de articulação e expressão facial/corporal. "Estes cinco parâmetros podem ser comparados a 'pedacinhos' de um sinal porque, no nível morfológico, eles podem ter significados, sendo, portanto, morfemas" (FELIPE, 2007, p. 148).

"A lógica da inclusão conforme a Lei da Declaração de Salamanca constitui a essência do ideal democrático fundado na lógica da igualdade consensual" (MONTEIRO, 2006, p. 299). Ainda, segundo a Declaração de Salamanca (BRASIL, 1994), a inclusão deve ocorrer independentemente da condição física, social e linguística do indivíduo; devendo contemplar pessoas de diferentes capacidades cognitivas, origens, etnias, crenças ou classes sociais. Para tanto, torna-se necessário equipar e capacitar as instituições educacionais, de forma a atender a todos os estudantes sem distinção. Desta forma, os surdos passam a ter o direito de serem assistidos por um intérprete em Libras, conforme representado em uma classe de aula, em disciplina da área de exatas, no ensino formal, conforme figura 1. 


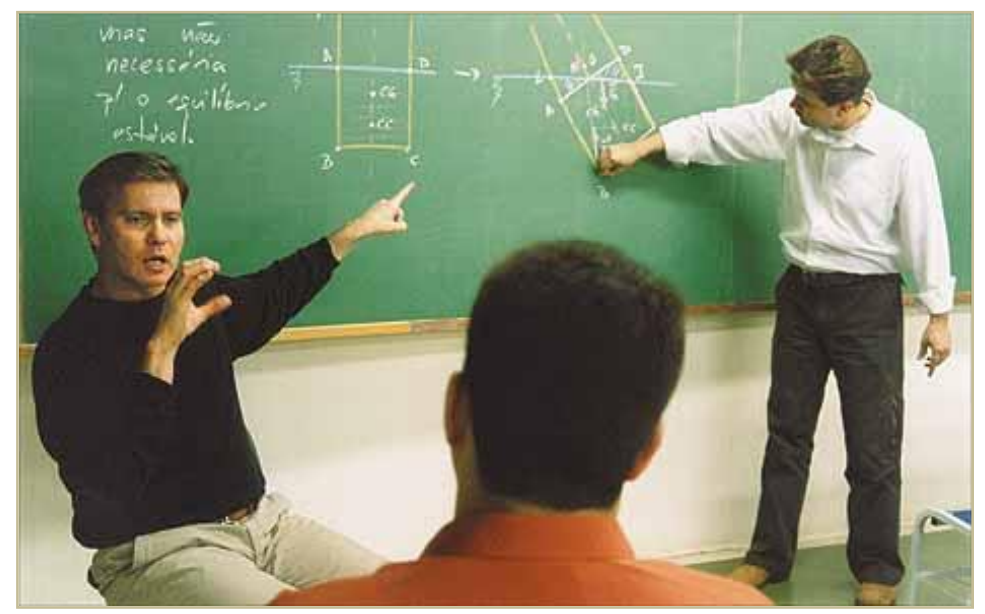

Figura 1 - Professor intérprete em Libras no ensino formal.

Fonte: CANCAONOVA.COM. Disponível na internet por http em: <http://blog.cancaonova.com/maosqueevangelizam/tag/utilidade-publica/>. Acesso em 05 abr. 2014.

Em setembro de 2012, a mídia divulgou amplamente o fechamento das escolas especiais públicas, no intuito de promover a inclusão dos deficientes na sociedade. Esta divulgação provocou uma reação da população que através das redes sociais lançaram diversos manifestos em repúdio a esta iniciativa. É ainda questionável a qualidade desta inclusão, já que, o processo é extremamente recente e as escolas públicas já sofrem com problemas estruturais físicos, para o atendimento dos demais alunos, o que dirá da integração de seus novos discentes com deficiências?

A Lei da Libras (lei $n^{\circ} 10.436$ de 24 de abril de 2002) foi regulamentada pelo decreto $n^{\circ} 5626$ de 22 de dezembro de 2005, que esclarece: "Para a educação destes, Libras se tornou disciplina obrigatória nos cursos de licenciatura e pedagogia no intuito de proporcionar ao aluno acadêmico o contato com a língua de sinais, entender os seus parâmetros, legislações e importância".

"É direito deles a tradução e interpretação de libras e língua portuguesa, é dever do governo e educadores desenvolver e adotar mecanismos alternativos para avaliação de conhecimentos expressos em libras", decreto no 5626 de 22 de dezembro de 2005.

As questões preocupantes são além dos equipamentos e pessoal capacitado, as metodologias ainda são experimentais no ensino no Brasil. O decreto $n^{\circ} 5626$ de 22 de dezembro de 2005, esclarece que: "é dever do governo disponibilizar equipamentos, acesso às novas tecnologias de informação e comunicação, bem como recursos didáticos para apoiar a educação de alunos surdos". Que recursos são estes? O que fazer em relação á diversidade cultural? Os métodos serão eficientes para todos, considerando a extensão de tradições, hábitos e cultura? Estas são algumas questões que devem ser analisadas.

\subsection{Inclusão dos deficientes auditivos nas escolas}

Em Belo Horizonte, desde 1994, há uma Lei Municipal de no 6.701/94, que garante vagas escolares para os alunos com deficiências nas escolas regulares e especiais do município. Os alunos com deficiências serão atendidos na rede pública municipal ou em escola particular conveniada, conforme previsto no art. 18 das Disposições Transitórias da Lei Orgânica do Município de Belo Horizonte. 
Outra Lei Municipal de Belo Horizonte, a Lei Municipal no 6.590/94, que dispõe sobre a implantação de ensino especial nas escolas públicas municipais e determina que o município adote sistema especial de ensino nas escolas da rede pública municipal, visando à plena integração e o atendimento adequado a deficientes físicos e mentais e a superdotados.

De acordo com cartilha da inclusão, da Secretaria de Desenvolvimento Social e Esportes - SEDESE, do Governo do Estado de Minas Gerais (2006), o sistema especial de ensino abrangerá o pré-escolar e todo o primeiro grau, com reciclagem de seus professores e servidores e deverá adotar uma infraestrutura física e de equipamentos adequados à satisfação das exigências dessa lei.

A Lei Estadual no 10.379, de 10 de janeiro de 1991, no seu art. 3ㅇ, determina que "fica incluída no currículo da rede pública estadual de ensino, estendendo-se aos cursos de magistério, formação superior nas áreas das ciências humanas médicas e educacionais, e às instituições que atendem ao aluno portador de deficiência auditiva, a Língua Brasileira de Sinais".

Em Belo Horizonte, há a Lei no 8.122/00, que acrescenta parágrafo ao art. 30 da Lei $n$ - 8.007/00, que determina que o poder executivo garanta que a linguagem brasileira de sinais - Libras - seja reconhecida como linguagem oficial no município como forma de eliminação de barreiras na comunicação. O executivo também estabelecerá mecanismos e alternativas técnicas que tornem acessível mensagem oficial à pessoa portadora de deficiência sensorial e com dificuldade de comunicação, para garantir-lhe o direito de acesso à informação.

Deve-se entender que a Libras se caracteriza como "[...] uma língua visualespacial articulada através das mãos, das expressões faciais e do corpo. É uma língua natural usada pela comunidade surda brasileira" (QUADROS, 2004, p.19). Este leque de possibilidades poderia contribuir para a comunicação dos alunos portadores de deficiência auditiva durante as aulas. Porém, este aluno possui restrições perante a formalidade recorrente ao método de aprendizagem no ensino das escolas padrões.

O ato de copiar o conteúdo em sala de aula, por exemplo, é uma dificuldade para este estudante. Conforme Quadros (2004), o aluno que escuta pode parar de olhar para o professor e copiar o conteúdo e as observações. O aluno com deficiência auditiva, por sua vez, se parar o contato visual para com o seu interprete perderá obviamente aquilo que está sendo expresso. Já que a comunicação depende exclusivamente da visão como receptor. Dessa forma, busca-se desenvolver uma solução que permita ao aluno deficiente um melhor aproveitamento em sala de aula.

\section{INICIATIVAS TECNOLOGIAS ASSISTIVAS}

O desenvolvimento de tecnologias que nos auxiliem em tarefas diárias é comum e a cada dia somos surpreendidos com ideias irreverentes e sustentáveis, já no campo da educação uma ferramenta tecnológica que possa auxiliar o aluno didaticamente é o diferencial de uma aprendizagem realmente efetiva e o mote central ao estudo em andamento. "Não podemos impedir a tecnologia, e não há razão para isso. Ela é útil. Mas podemos mudar o direcionamento da inovação e insistir que as pessoas vêm antes da tecnologia." (THACKARA, 2008, p. 16).

Segundo Botelho (2009), não ter uma língua compartilhada define uma situação de desigualdade cognitiva e interativa imensa e se tratando de um deficiente auditivo, aquele que compreende e interage com o mundo por meio de experiências 
visuais. Ou seja, não compartilha da mesma linguagem dos ouvintes, isso se torna um desafio para educação, conduzir positivamente essa diferença sendo a linguagem fator fundamental ao desenvolvimento cognitivo do sujeito sociocultural.

Assim, para o ensino-aprendizagem, campos promissores seguem a conversão automática de texto em Língua Gestual. Esta tecnologia utiliza avatares ${ }^{2}$ em 2D ou 3D para traduzir, automaticamente, qualquer texto em língua gestual. Não se trata de soletrar as palavras através de gestos, mas de traduzir, por exemplo, um texto escrito em português para libras. Esta tarefa enfrenta os mesmos problemas que qualquer outro sistema de tradução automática, que se nomeia a compreensão do contexto. Contudo, neste domínio ocorrem avanços significativos. Esta tecnologia aliada ao reconhecimento da fala permitirá à comunidade de surdos a uma acessibilidade ampliada a documentos scripto-audio-visuais, possibilitando a legendagem automática de documentos vídeo e tradução de documentos texto e/ou áudio em Língua Gestual, conforme Correia et al (2012).

Softwares de tradução automática de texto em símbolos poderão também ser úteis para uma compreensão mais aprofundada de diversos tipos de textos. Correia et al (2012) apresenta como exemplos, o Escrita com símbolos e o inVento, aprovados pelo Ministério da Educação de Portugal.

A seguir, algumas tecnologias elaboradas para contribuir nas atividades de comunicação, necessárias para o sistema de ensino, dos portadores de deficiência auditiva:

\section{- Mobile Lorm Glove}

A luva de comunicação na linguagem Lorm, é um projeto desenvolvido por pesquisadores e doutorandos da Berlin University of the Arts (Design Research Lab) no intuito de ampliar a integração social de pessoas "surdo-cegas".

\section{- ProDeaf}

O ProDeaf Tradutor para LIBRAS, desenvolvido pela ProDeaf Tecnologias Assistivas com o patrocínio do Grupo Bradesco Seguros. O ProDeaf foi elaborado em 2010 como pesquisa no curso de mestrado em Ciências da Computação da Universidade Federal de Pernambuco.

- Hand Talk

É um software criado pelos sócios Ronaldo Tenório, Carlos Wanderlan e Thadeu Luz. O Hand Talk App por sua vez recebeu em fevereiro de 2013, o prêmio de melhor aplicativo na categoria de Inovação Social no concurso WSA-Mobile promovido pela ONU nos Emirados Árabes. O software Hand Talk App assim como o ProDeaf, é um tradutor de língua portuguesa para LIBRAS intermediado por um avatar em modelagem de simulação tridimensional.

O software reconhece as palavras de uma mensagem de texto, por exemplo, e o personagem Hugo interpreta o significado em Libras, conforme demonstrado na figura 2. O caminho inverso - a possibilidade de responder em libras que seriam convertidas em texto - faz parte dos planos para uma segunda etapa do projeto. Os cuidados agora estão em aperfeiçoar os códigos que funcionam como cérebro do avatar, declara o diretor executivo do projeto, Ronaldo Tenório: - "Quanto mais for usado, mais precisas se tornam as traduções".

\footnotetext{
${ }^{2}$ Conforme Correia et al (2012) um avatar é a representação gráfica de um utilizador numa comunidade virtual.
} 
Hugo também ajuda na interpretação de imagens que tenham texto, como a capa de um jornal. O usuário fotografa a página e a imagem é varrida pelo programa em busca de caracteres. Um sistema de reconhecimento lê o conteúdo, que é traduzido em gestos ${ }^{3}$.

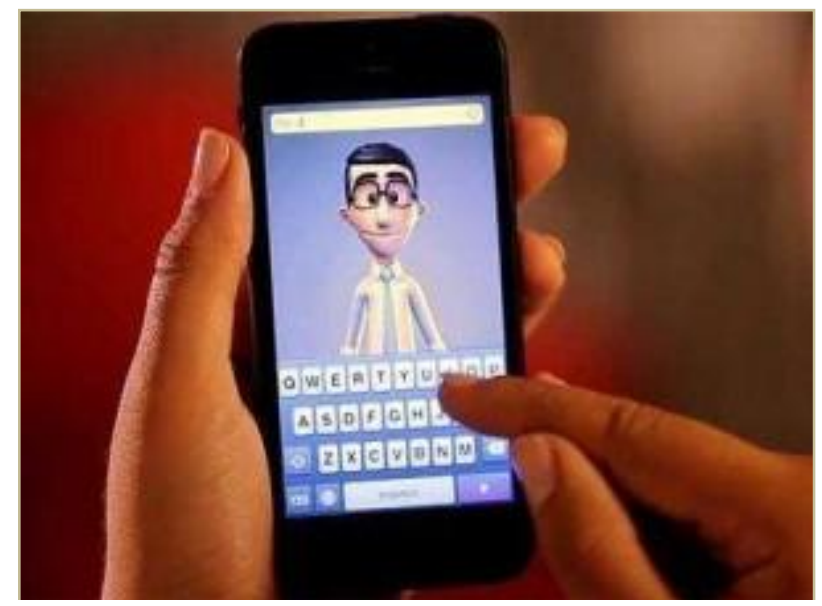

Figura 2 - Software Hand Talk App. Personagem Hugo, interpreta o significado em Libras.

Fonte: JEACONTECE.COM.BR. ONU premia software brasileiro que traduz mundo digital para surdos. Disponível na internet por http em: <http://jeacontece.com.br/?p=41639>. Acesso em 10 abr. 2014.

\section{DESIGN PARA INCLUSÃO}

A recente conquista dos surdos na sociedade compartilha com o Design quase a mesma brevidade, por isso a perspectiva do design digital como um caminho para a educação inclusiva na contemporaneidade.

O foco do design universal e o design social é aplicar usabilidade à grande maioria da diversidade humana. "Sendo assim, o design tem a chance de buscar diferentes formas de incluir pessoas no processo de desenvolvimento, como no design participativo. Desta forma, é gerado espaço para a inclusão de conceitos de diversidade ao invés de normalidade" (BIELING; JOOST, 2012, p. 02).

De acordo com o mesmo autor, "A maioria das soluções é composta de práticas sociais - algumas muito antigas que evoluíram em outras sociedades e outros tempos." Por sua vez "O design está profundamente enredado ao nosso dia a dia, e, portanto, sempre conectado à esfera social. Logo, nós poderíamos pensar em design como algo relacionado a mudanças sociais" (BIELING; JOOST, 2012, p. 01).

Segundo Duarte Junior (2002), a movimentação de valores e significados no interior de uma cultura. Ela sucede através de símbolos, com os quais, " [...] o homem transcende a simples esfera física e biológica, tomando o mundo e a si próprio como objetos de compreensão" (DUARTE JUNIOR, 2002, p.15).

A comunicação visual é inerente ao Design Gráfico e a Arte, a utilização de mapas, infográficos, pinturas e diagramas é um importante meio no qual os seres humanos podem trocar informações. A alfabetização visual pode auxiliar a percepção estética estimulando um melhor desempenho escolar.

3 JEACONTECE.COM.BR. ONU premia software brasileiro que traduz mundo digital para surdos. Disponível na internet por http em: <http://jeacontece.com.br/?p=41639>. Acesso em 10 abr. 2014. 


\section{CONCLUSÕES}

Quanto à história da educação inclusiva para com deficientes auditivos foi relatado em síntese que, no início do século XVI registraram-se experiências do médico pesquisador italiano Gerolamo Cardano. Relatou-se ainda que Pedro Ponce de Leon (1520 - 1584) cria na Espanha a primeira escola de surdos e XVIII, na França, surge Abade Charles Michel de L'Epée que inicia com as pessoas surdas a língua de "Sinais Metódicos". No Brasil, D. Pedro II apoia a primeira criação de escola para surdos em 1857, no Rio de Janeiro pelo professor surdo francês, Ernest Huet. Contudo, a inclusão é realizada em passos lentos, e pontuais. Nem todas as sociedades seguiram os mesmos caminhos para a inclusão de deficientes no ensino formal.

Quanto à regulamentação da Educação inclusiva no ensino, foi relatado que, em 2002, a Libras foi decretada como forma de comunicação e expressão formal em todo o território brasileiro e a segunda língua é o português. A Linguagem em Libras se configura na comunicação através das mãos, movimento, orientação das mãos, ponto de articulação e expressão facial e corporal. Porém, com todas as leis e normas, este processo de adaptação do ensino é bastante lento, por motivos diversos.

Em 2012, a mídia divulgou o fechamento das escolas especiais públicas, no intuito de promover a inclusão dos deficientes na sociedade. Condição que não ajuda a melhor a implantação de novos sistemas nas escolas. Sabe-se que é dever do governo disponibilizar equipamentos, acesso às novas tecnologias de informação e comunicação, bem como recursos didáticos para apoiar a educação de alunos surdos. No entanto, são tantos outros deveres do governo, em situações que requerem menores emprenho, e mesmo assim, não há investimentos adequados.

Quanto à inclusão de portadores de deficiência auditiva em escolas, em Belo Horizonte, desde 1994 há uma Lei Municipal de no 6.701/94, que garante vagas escolares para os alunos com deficiências nas escolas regulares. Mas, sabe-se que as escolas municipais necessitam de vagas e de melhor estrutura para todos os demais estudantes. Uma das escolas da pesquisa, Escola Estadual Francisco Sales, conforme figura 3, está localizada próximo à área central e possui boas instalações para atender aos alunos. Mas ainda é a exceção.

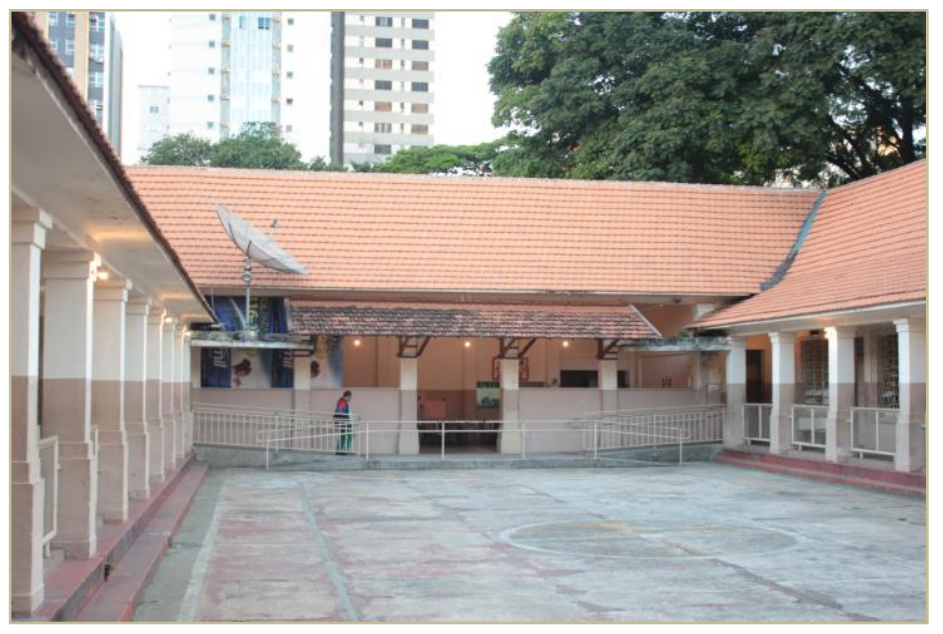

Figura 3 - Escola Estadual Francisco Sales

Fonte: Elaborado pelo autor, com base na pesquisa realizada, 2014.

Todos os regulamentos e leis visam facilitar a inclusão e estabelecer mecanismos e que tornem acessível às condições de aprendizagem para os portadores 
de deficiência sensorial e com dificuldade de comunicação, visando garantir-lhe os direitos. Mas, não há uma pesquisa conhecida que certifique que estas ações se instalaram, conforme determinam as leis.

Quanto às iniciativas tecnologias inclusivas e a participação do design neste processo, são apresentados resultados positivos. Os investimentos no setor de tecnologias aumentam gradativamente. Também se destacam as novas contribuições do design, seja universal, inclusivo, social ou participativo, proporcionando abertura neste setor para novos projetos. O objetivo é verificar as tecnologias existentes, suas qualidades e deficiências e trabalhando em parceria com os surdos criar uma nova tecnologia que permita de forma efetiva uma igualdade de condições de aprendizagem em sala de aula. As questões como espaço, posicionamento dos alunos, etc. são cruciais para o aluno com deficiência auditiva. É um longo caminho a percorrer, mas acredita-se que com a utilização das ferramentas de Design inclusivo e respeitando a cultura dos surdos podemos atingir os resultados esperados.

\section{REFERÊNCIAS}

ASSEMBLEIA LEGISLATIVA DO ESTADO DE MINAS GERAIS. Lei Estadual no 10.379, de 10 de janeiro de 1991. Disponível na internet por http em: $<$ http://crv.educacao.mg.gov.br/SISTEMA CRV/banco objetos crv/\%7B90AA857AF928-4861-A7F3-

44076BD2BB60\%7D LEI\%2010379,\%20de\%2010\%20DE\%20JANEIRO\%20DE\%201991.p df>. Acesso em $10 \mathrm{abr} .2014$.

BIELING, Tom; JOOST, Gesche. Design contra a Normalidade. Traduzido do inglês por Paulo Ortega. In: V!RUS, São Carlos, n. 7, Jun. 2012. Disponível na internet por http em: $<$ http://www.nomads.usp.br/virus/virus07/secs/invited/virus 07 invited 2 pt.pdf $>$. Acesso em 20 jan. 2014.

BOTELHO, Paula. Educação inclusiva para surdos: desmistificando pressupostos. 2009. Disponível na internet por http em: $<$ http://proex.pucminas.br/sociedadeinclusiva/anaispdf/educsurdos.pdf $>$. Acesso em 10 abr. 2014.

BRASIL. Decreto no 5.626, de 22 de dezembro de 2005. Regulamenta a Lei no 10.436, 24 abr. 2002, que dispõe sobre a Língua Brasileira de Sinais - Libras e o art. 18 da Lei no 10.098, de 19 dez. 2000. Brasília, 22 dez. 2005. Disponível na internet por http em: <http://www.planalto.gov.br/ccivil 03/ ato2004-2006/2005/decreto/d5626.htm>.

Acesso em 10 abr. 2014.

BRASIL. Lei no 10.436, de 24 de abril de 2002. Dispõe sobre a Língua Brasileira de Sinais. Brasília, p. 01, 24 abr. 2002. Disponível na internet por http em: <http://www.camara.gov.br/proposicoesWeb/prop mostrarintegra;jsessionid=3D4B0 1273D5015CA7D206E8781EE313F.node2 ?codteor=715147\&filename=LegislacaoCitada +-PL+6428/2009>. Acesso em 10 abr. 2014.

BRASIL. Ministério da Justiça, Secretaria dos Direitos Humanos. Declaração de Salamanca e linha de ação. 2 ed. Brasília: CORDE, 1994. 
BRITO, Lucinda Ferreira. Integração Social \& educação de surdos. Rio de Janeiro: Babel, 1993.

CÂMARA MUNICIPAL DE BELO HORIZONTE. Lei Orgânica do Município de Belo Horizonte de no 6.701/94. Disponível na internet por http em: <http://www.cmbh.mg.gov.br/images/stories/secren/LOMBH\%20consolidada.pdf $>$. Acesso em 10 abr. 2014.

CÂMARA MUNICIPAL DE BELO HORIZONTE. Lei Orgânica do Município de Belo Horizonte de no 6.590/94. Disponível na internet por http em: $<$ https://www.google.com.br/search?q=Lei+Municipal+n\%C2\%BA+6.590\%2F94\&oq=Le i+Municipal+n\%C2\%BA+6.590\%2F94\&aqs=chrome..69i57.4624j0j7\&sourceid=chrome

\&es sm=93\&ie=UTF-8>. Acesso em 10 abr. 2014.

CÂMARA MUNICIPAL DE BELO HORIZONTE. Lei Orgânica do Município de Belo Horizonte de no 8.122, de 29 de novembro de 2000. Disponível na internet por http em: $<$ https://www.google.com.br/search?q=Lei+n\%C2\%BA+8.122\%2F00+BELO+hORIZ ONTE\&oq=Lei+n\%C2\%BA+8.122\%2F00+BELO+hORIZONTE\&aqs=chrome..69i57.7320j0j 7\&sourceid=chrome\&es sm=93\&ie=UTF-8>. Acesso em 10 abr. 2014.

CANÇÃONOVA.COM. Disponível na internet por http em: $<$ http://blog.cancaonova.com/maosqueevangelizam/tag/utilidade-publica/>. Acesso em 05 abr. 2014.

CORREIA, Secundino; CORREIA, Patrícia; FRASSINETTI, Ese de Paula. Acessibilidade e desenho universal. 2012. Disponível na internet por http em: $<$ http://atividades.imagina.pt/uploads/cnoti/PDF/desenho universal.pdf > . Acesso em 19 mar. 2014.

DUARTE JÚNIOR, João Francisco. Fundamentos estéticos da educação. 9. ed. Campinas: Papirus Editora, 2002.

FELIPE, Tanya A. Libras em contexto: curso básico: livro do estudante. 8 ed. Rio de Janeiro: WalPrint Gráfica e Editora, 2007.

GOLDFELD, Márcia. A criança surda: linguagem e cognição numa perspectiva sóciointeracionista. 2o edição. São Paulo: Plexus Editora, 2002.

JANNUZZI, Gilberta de Martino. Educação do Deficiente no Brasil: dos primórdios ao início do século XXI. 1. ed. Campinas: Autores Associados, 2004.

JEACONTECE.COM.BR. ONU premia software brasileiro que traduz mundo digital para surdos. Disponível na internet por http em: <http://jeacontece.com.br/?p=41639>. Acesso em 10 abr. 2014.

MARTINS, Heloisa Helena. Metodologia Qualitativa de Pesquisa. In: Educação e Pesquisa, São Paulo, v.30, n.2, maio/ago. 2004. Disponível na internet por http em: <http://www.scielo.br/pdf/ep/v30n2/v30n2a07.pdf>. Acesso em 10 abr. 2014. 
MONTEIRO, Myrna Salerno. História dos Movimentos dos Surdos e o reconhecimento da Libras no Brasil. Educação Temática Digital, Campinas, v.7, n.2, p.295-305, jun. 2006. ISSN: 1676-2592. Disponível na internet por http em: <file:///C:/Users/MEGAWARE/Downloads/Educa\%C3\%A7\%C3\%A3o Tem\%C3\%A1tica Digital, Campinas-7(2)2006-

historia dos movimentos dos surdos e o reconhecimento da libras no brasil.pdf >. Acesso em 10 abr. 2014.

PARASURAMAN, A. Marketing Research. Toronto: Addison-Wesley Publishing company, 1986.

POKER, Rosimar Bortolini. Troca simbólica e desenvolvimento cognitivo em crianças surdas: uma proposta de intervenção educacional. UNESP, 2001. 363p. Tese (doutorado) - Universidade do Estado de São Paulo, Curso de Pós-Graduação em Filosofia.

QUADROS, Ronice Müller de. $\mathbf{O}$ tradutor e intérprete de língua brasileira de sinais e língua portuguesa. Secretaria de Educação Especial; Programa Nacional de Apoio à Educação de Surdos. Brasília: MEC; SEESP, 2004.

SECRETARIA DE DESENVOLVIMENTO SOCIAL E ESPORTES - SEDESE. Cartilha da inclusão: Direitos da Pessoa com Deficiência. Belo Horizonte, Governo do Estado de Minas Gerais, 2006. Disponível na internet por http em: <http://www.oabmg.org.br/pdf/Cartilha_Inclusao.pdf>. Acesso em 10 abr. 2014.

THACKARA, John. Plano B: o design e as alternativas viáveis em um mundo complexo. Tradução do original inglês para o português de Cristina Yamagami. São Paulo: Saraiva: Versar, 2008. 341 p. Título original: In the bubble: designing in a complex world.

Agradecimentos:

FAPEMIG - Fundação de Amparo a Pesquisa do Estado de Minas Gerais.

CEDTec - Centro de Estudos em Design \& Tecnologia

Escola Estadual Francisco Sales 